\title{
Usefulness of Plastic Hoffman Apparatus in Chemistry Classes: A Case Study of Its Implementation with High School Teachers
}

\author{
Muhamad Hugerat ${ }^{*}$, Ahmad Basheer, Naji Kortam \\ SALiS Center, The Academic Arab College for Education, 22 Hachashmal St., Haifa, Israel \\ Email: *muha4@macam.ac.il
}

Received April 12 $2^{\text {th }}, 2013$; revised May $13^{\text {th }}, 2013$; accepted May 22 $2^{\text {nd }}, 2013$

\begin{abstract}
Copyright (C) 2013 Muhamad Hugerat et al. This is an open access article distributed under the Creative Commons Attribution License, which permits unrestricted use, distribution, and reproduction in any medium, provided the original work is properly cited.

In this article we present simple and feasible idea to introduce electrolysis experiments using accessible materials in the classroom. We use plastic syringes and pipettes to build different shapes of Hoffman apparatus for electrolysis. This activity was introduced to a group of 20 teachers from the Arab sector in Israel to examine their impressions about the activity and investigate the feasibility of implementing the activity in their classrooms.
\end{abstract}

Keywords: Electrolysis Workshop; Professional Development of Teachers; Case Study; Accessible Materials; Plastic Apparatus

\section{Introduction}

Professional development of educators at different levels is described by many researchers as a central lever leading to change and improve the capabilities and achievements of the education system (Scandholtz \& Scribner, 2006).

Elliote (1999) emphasizes that it is very important to carryout local studies, and case studies to examine the interaction between local and global dimensions related to the development of teachers.

Teachers can act as powerful mediators in introducing change. Their decision to implement a new project depends on their satisfaction from the current situation and their expectations from the contribution of the project in improving their teaching (Wallace \& Louden, 1998; Zidani, Kortam, \& Hugerat, 2003).

In order to introduce a change, the teacher, himself, must go through a learning process (Wheeler et al., 1995). In this process, the teacher is an active partner in the creation of change. This involvement is a constructivist teaching model, which is essential in the introduction of such process.

In a study among elementary school teachers in Israel, BenChaim et al. (1994) found that training workshops encourage the implementation of approaches, attitudes and scientifictechnological—and social literacy among the participating teachers.

In this article we present simple and feasible idea to introduce the microscale electrolysis experiments using accessible materials in the classroom. We use plastic syringes and pipettes to build different shapes of Hoffman apparatus for electrolysis. We introduce this activity for high school teachers and we examine the impact of this implementation.

Starting from the last century, electrolysis of water solutions has been widely demonstrated to students in secondary schools,

\footnotetext{
${ }^{*}$ Corresponding author.
}

or in a first-year college in order to illustrate oxidation-reduction reactions as well as to demonstrate the use of an external source of energy for driving non-spontaneous chemical reactions (Hendricks \& Williams, 1982; Hugerat, 2006, 2008; Hugerat et al., 2009; Shakhashiri, 1992; Zhou, 1996).

A Hofmann apparatus is an apparatus for electrolyzing water, invented by August Wilhelm von Hofmann. It consists of three joined upright cylinders, usually glass. The inner cylinder is open at the top to allow the addition of water and an ionic compound, such as a small amount of sodium sulfate, to improve conductivity. A platinum electrode is placed inside the bottom of each of the two outer cylinders, connected to the positive and negative terminals of a source of electricity. Gaseous oxygen forms at the anode and gaseous hydrogen forms at the cathode when a current runs through the Hofmann's apparatus. Each gas displaces water and collects at the top of the two outer tubes (Hugerat, 2006, 2008; Hugerat \& Schwarz, 2008; Hugerat et al., 2009; Zhou et al., 2005).

Microscale chemistry is the reduction of chemicals use to the lowest level at which experiments can be effectively performed. It offers a safer way to perform chemical experiments by using smaller quantities of chemicals. Microscale experiments are conducted without compromising the quality or standard of chemical applications in educational institutions and the experimental industry. The Benefits of Microscale Chemistry are: reduces chemicals use by promoting waste reduction at the source; improves laboratory safety (air quality, reduced exposure, and spills); saves money; decreases experiment time; teaches students alternatives to conventional chemistry (Singh et al., 1999; Zhou et al., 2005).

For microscaling, the "Hoffmann Apparatus" the container, the electrodes, the electrolyte, and the power supply are replaced by smaller units; uses narrow 3-mL test tubes, insulated copper wire (for the anode they are combined with a pencil lead), diluted sodium hydroxide solution, or sodium sulfate solution 
with drops of universal indicator is introduced as neutral electrolyte. A cheap AC/DC adaptor or a 9-Volt battery is used as power supply (Hugerat, 2006, 2008; Hugerat et al., 2009; Hugerat \& Schwarz, 2008; Zhou et al., 2005).

\section{Methodology}

The workshop is one of the good ways to expose teachers to innovations in building new devices on chemistry experiments. It also opens new horizons for teachers to be more creative in the construction of their own devices to use disposable materials that have no adverse impact on the environment (Thompson \& Soyibo, 2002). The general idea behind this article is to investigate the effect of implementing the activity "Plastic Huffman Apparatuses" with teacher participants in the Academic Arab College for Education in Israel. The main idea of the workshop is to expose simple activity for electrolysis, such as "plastic Hoffman apparatus" for teachers and to encourage teachers to be active and creative in building their apparatuses. The workshop for teachers took place in the laboratory of the Academic Arab College for Education in Israel during December 2011.

The workshop consisted of four meetings of eight contact hours each. During the workshop, selected topics in electrolysis were introduced (Table 1). The main topic was electrolysis through the implementation of an activity titled "Plastic Huffman Apparatuses".

The participants in the workshop were 20 teachers from the Arab sector in Israel; public and private high schools. Their participation in the workshop was mandatory; they were selected from different schools by the science inspector. They earned hours toward their recertification.

The activity was presented in a full day (4 days) session of eight hours (every day) in which the participants were introduced to the concept of electrolysis and different methodologies designed to enhance their content knowledge about the topic and the pedagogical content knowledge to implement this topic in their classrooms. The last two meeting focused on the usefulness of plastic Huffman apparatuses for electrolysis (Table 1). The last meeting in the workshop focused on the creativity of teachers, the teachers were asked to build their own plastic Huffman apparatuses using plastic and disposables materials.

This activity was introduced to a group of 20 teachers to collect their impressions about the activity and investigate the feasibility of implementing the activity in their classrooms. Following the activity, the researchers presented the participants with a paper survey to collect their impressions about the activity, their previous knowledge about the topic of electrolysis and their predictions of the benefits to their students through the implementation of this activity in their classrooms.

Table 1.

Syllabus of the course of the workshop.

\begin{tabular}{rll}
\hline Hours Topics & Type of presentation \\
\hline 8 & Introduction to Electrolysis & Lecture and Demonstration \\
8 & $\begin{array}{l}\text { Conventional Huffman } \\
\text { Apparatuses }\end{array}$ & $\begin{array}{l}\text { Demonstration and Active } \\
\text { Experimentation }\end{array}$ \\
& $\begin{array}{l}\text { Plastic Huffman } \\
\text { Apparatuses }\end{array}$ & Demonstration and Active \\
& $\begin{array}{l}\text { Creativity: Design of Plastic } \\
\text { Huffman Apparatuses }\end{array}$ & Creative and Active Experimentation \\
\hline
\end{tabular}

The following represents the series of experiments implemented during the activity.

\section{Plastic Hoffman Apparatuses for Electrolysis}

Advantages of doing these demonstrations:

- Students are encouraged to experiment and develop their own electrolysis experience. Experiments can be done quickly.

- The creativity of students will be stimulated: They can find individual solutions for a given problem. Their independence increases.

- Micro-scale saves time. It leaves more opportunities for conversation, reflection and evaluation while protecting the environment by using small amounts of chemicals: fewer chemicals, less waste (less is more).

- Micro-scale saves money: special laboratory materials are replaced by disposable items commonly found in daily life, or easily acquired.

- Increasing sensitivity to the environment: becoming aware of problems related to consumption, recycling and raw materials used in daily life.

\section{Plastic Syringe Hoffman}

\section{Materials and chemicals}

Two 5-ml plastic syringe, wooden test tube stand, bottom of a disposable plastic cup container, two blunted hypodermic needles as electrodes, 2 insulated copper wires with crocodile clips, $9 \mathrm{~V}$ battery, sodium sulphate solution in red cabbage extract.

1. Connect the two plastic syringes from the bottom as shown in Figures 1 and 2.

2. Pierce the disposable plastic cup container on the wooden stand from the downside with the two blunted needles.

3. Totally fill the two plastic syringes with the electrolyte (sodium sulphate solution in red cabbage extract).

4. Carefully turn the bottles upwards down and place them tightly on the needles.

5 . Add $5 \mathrm{ml}$ of the electrolyte solution to the disposable plastic cup container.

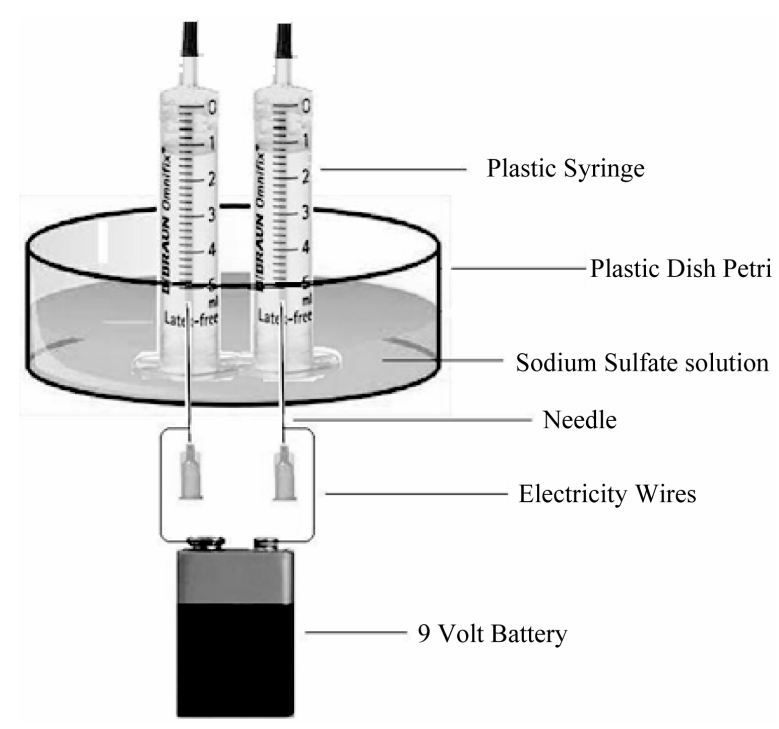

Figure 1.

Scheme of the plastic Huffman apparatus. 

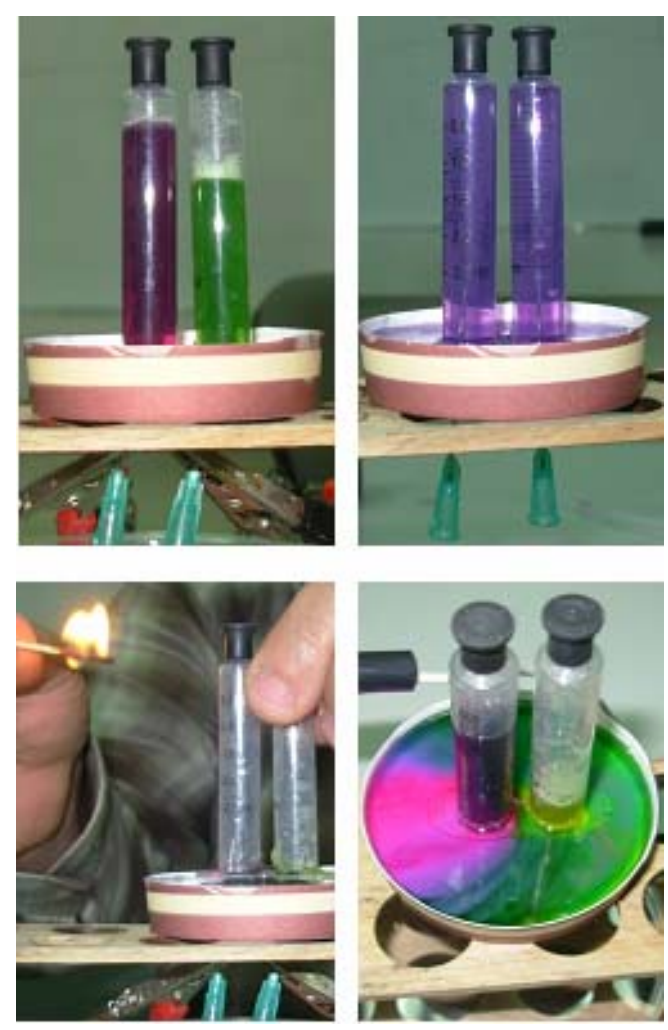

Figure 2.

Plastic Syringe Huffman apparatus experiment.

6. Connect the needles acting as electrodes to the power supply (9 V battery).

\section{Hazards}

Although the power source ( $9 \mathrm{~V}$ battery) used is relatively weak, electrodes should not be handled while cells are operating. Care should be exercised when testing the hydrogen gas with a burning splint, be careful of explosive hydrogen and oxygen mixtures. Handle the sodium sulfate with care; they can cause skin irritation. Wear gloves and goggles throughout the experiments. Be careful during your work with the sharp needles, we suggest to cut the narrow part of the needle.

Observations and Explanations. Electrolysis of water is a key chemical reaction, which is very often demonstrated for students. When an electrical current (DC) is passed through a water solution, oxygen gas and hydrogen ions are produced at the anode while hydrogen gas and hydroxide ions are released at the cathode side; see the equations (Hendricks \& Williams, 1982; Hugerat, 2006; Shakhashiri, 1992; Zhou, 1996).

Cathodic Reduction: $4 \mathrm{H}_{2} \mathrm{O}+4 \mathrm{e}^{-} \rightarrow 4 \mathrm{OH}_{(\mathrm{aq})}^{-}+2 \mathrm{H}_{2(\mathrm{~g})}$

Anodic Oxidation: $2 \mathrm{H}_{2} \mathrm{O} \rightarrow 4 \mathrm{H}_{(\mathrm{aq})}^{+}+\mathrm{O}_{2(\mathrm{~g})}+4 \mathrm{e}^{-}$

Redox Reaction: $6 \mathrm{H}_{2} \mathrm{O} \rightarrow 2 \mathrm{H}_{2(\mathrm{~g})}+\mathrm{O}_{2(\mathrm{~g})}+4 \mathrm{H}_{(\text {aq })}^{+}+4 \mathrm{OH}_{(\text {aq })}^{-}$

The plant pigments presents in red cabbage, anthocyanin, turn to red in acidic solutions, purple in neutral solutions, and green to yellow in basic solutions. It can be clearly observed after a few minutes of electrolysis that the color of the indicator turns as the following (Figure 2):

Anode: peuple $\rightarrow$ red

Cathode: peuple $\rightarrow$ green

The intensity of the color depends on the change in the $\mathrm{pH}$ of the solution near the electrodes. As a result of electrolysis of water, bubbles of hydrogen gas as well as hydroxide ions accumulate in the cathode side. On the other hand, bubbles of oxygen gas and also hydrogen ions are produced in the anode side, and the volume ratio is 2:1 $\left(\mathrm{H}_{2} / \mathrm{O}_{2}\right)$ (Figure 2).

\section{Microscale Electrolysis in Two 3-ml Plastic Pipettes}

In this experiment the two half-cells are two 3-ml plastic pipettes (Figure 3), pierced by two injection needles, which have been closed before by heating and compressing their plastic ends. The pipettes are completely filled with a concentrated sodium sulfate solution in a red cabbage extract and placed into a 50-ml plastic cub with an electrolyte. This plastic cub acts as a salt bridge and as a stand (Figure 3). A 9-Volt battery is used as power supply.

\section{Observations and Explanations}

1. The indicator changes its colour to green in the cathode pipette; and to red in the anode pipette.

2. Two gases develop in a volume ratio 2 (cathode) to 1 (anode).

3. A fascinateur phenomenon can be demonstrated when the DC connections between both electrodes is reversed. Due to reversing the polarity of both electrodes. The initially anode become the cathode and the initially cathode is converted to anode. As a consequence of this change, acid-base neutralization occurs in the surrounding of each electrode due to the electrolysis of water. After changing the polarity equal volumes of gases

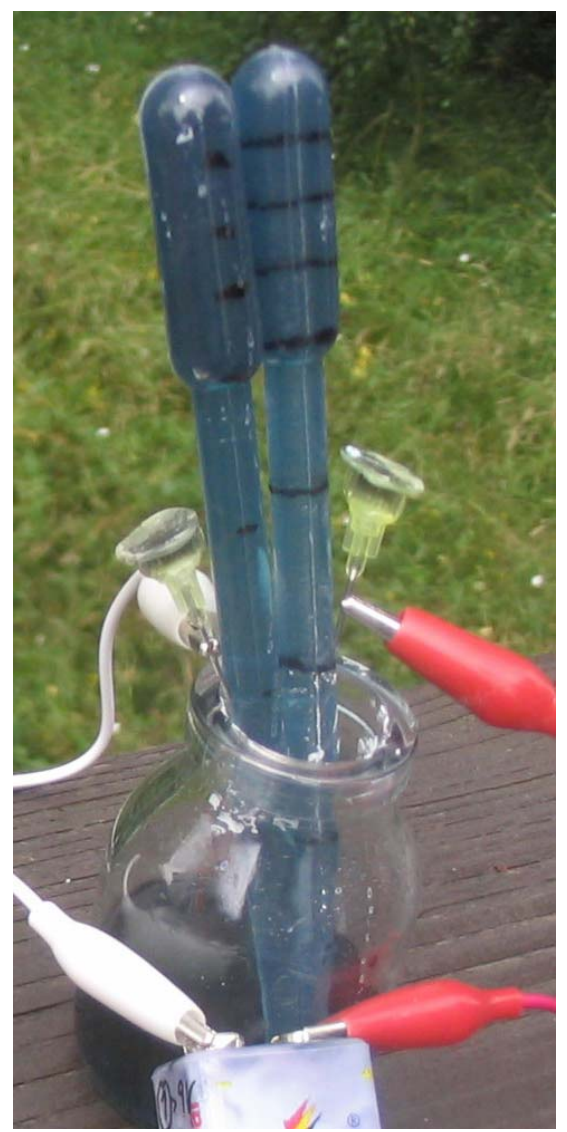

Figure 3.

Two 3-ml plastic pipettes electrolysis experiment. 
are formed in both pipettes.

4. After piercing the pipette heads with small closed hypodermic needles these gases can be ignited by the spark of a piezoelectric device: Fixing the pipette during the reaction results in a strong reduction of the gas volume. Water synthesis of oxyhydrogen gas in the pipette head. As the reactants disappear and the product is a liquid the volume is reduced very much.

$$
2 \mathrm{H}_{2(\mathrm{~g})}+\mathrm{O}_{2(\mathrm{~g})} \rightarrow 2 \mathrm{H}_{2} \mathrm{O}_{(\mathrm{l})}
$$

\section{Electrolysis in One Pipette}

In this experiment the cell is 3-ml plastic pipette, pierced by two injection needles, which have been closed before by heating and compressing their plastic ends, the two injection needles acting as electrodes. The pipette is completely filled with a concentrated sodium sulfate solution in a red cabbage extract and placed into one hole of a plastic 6-well plate; the end of the long tail of the plastic pipette dipped inside an another hole of the plastic 6-well plate which contain soap solution (Figure 4). A 9-Volt battery is used as power supply.

Observations and Explanations. When an electrical current (DC) is passed through a water solution, oxygen gas is produced at the anode while hydrogen gas produced at the cathode. These gases transferred through the long tail of the pipette to arrive to the soap solution and we observed bubbles over the soap solution. A simple method to check these gases (hydrogen and oxygen) is to bring a source of fire to the bubbles; immediately a weak sound of explosion is heard. This is a safety experiment because the amount of hydrogen and oxygen which we produced during the electrolysis are very small.

\section{Educational Component}

20 school teachers participated in this workshop doing this activity. Following the activity, the researchers presented the participants with a paper survey to examine their impressions about the activity, their previous knowledge about the topic of electrolysis and their predictions of the benefits to their students through the implementation of this activity in their classrooms.

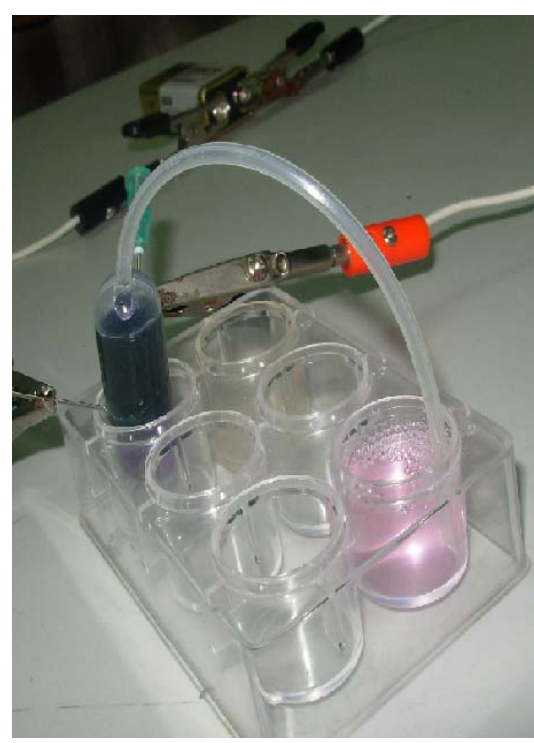

Figure 4

Electrolysis in one pipette in 6-well plate.
Some of the results from the analysis of the survey are:

1. Regarding previous knowledge about electrolysis, the majority of them stated that they gained this knowledge through formal education. And they have no idea about new developments about new apparatuses from the new science education journals, especially apparatuses from disposables materials such as plastic apparatuses.

2. When the teachers were asked if they taught electrolysis in their classrooms, the majority stated that they teach electrolysis using conventional methods. Some of them wrote that they used conventional Hoffman apparatus.

3. When they were asked to describe briefly whether the experiments presented in this workshop has helped them to understand the process of electrolysis in a better way. Most of them have answered that after the activity the concept of electrolysis became much clearer for them and that they can explain it to audiences clearly. As an anecdotal remark, one of the teachers stated that at the beginning of the workshop she had a very little knowledge on the subject, and doing these experiments has enlightened her about the topic and how to present it to her students. Most of the participants concluded that using these electrolysis experiments would allow their students to visualize what occurs during electrolysis. In the same manner, teachers commented that the experiments were presented in such a way that it is easy to implement and does not need a science laboratory. Some of them also expressed a clear gain in content knowledge using specific language to explain what occurred in the electrolysis, such as the production of acid/base in the anode/cathode and the liberation of $\mathrm{O}_{2}$ and $\mathrm{H}_{2}$.

4. When they were asked about the accessibility to disposable materials to implement the activity, the teachers believe that using disposable materials and a natural indicator such as red cabbage juice makes the experiments simpler, so they can think about other materials that they can use and if they do not have all the materials, they will be able to find a way to obtain them or provide alternate materials with which the experiment can be performed. Figure 5 shows an experiment which was designed by one of the teachers participating in the workshop. In the last part of the workshop, as we noted at the beginning was the important part which teachers were asked to design new equipment apparatus. As seen in the experiment (Figure 5) one the teacher built very simple experimental equipment apparatus for electrolysis. He took a syringe and used two needle electrodes, a battery of nine-volt current source, coffee cup as a stand and salt bridge and followed the electrolysis of tap water. As shown in this electrolysis device, he collected in the syringe oxygen and hydrogen gas. The teacher tested for oxygen and hydrogen when used with a match, the test is very safe because
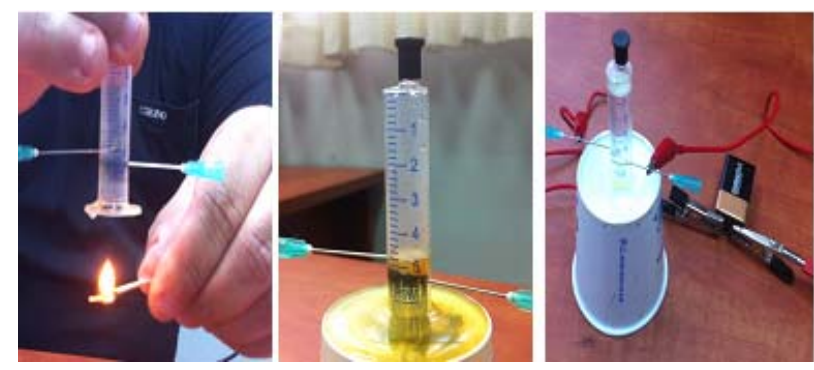

Figure 5.

Plastic syringe apparatus for electrolysis designed by a participating teacher in the workshop. 
of the small amount of gas generated. The teacher could also give an explanation for the product has a greenish yellow color (which is chlorine) and the solid brown is rust. More creative experiments using plastic materials were designed by other teachers in the workshop.

5. When they were asked about the possibility to implement this activity in the next academic year, the teachers expressed their intentions to implement some of these electrolysis activities in their classroom.

6 . The teachers believe that these activities will enhance the learning process in their classroom, claiming that today most of their students are visual learners and this kind of activity will motivate and engage them in the learning process of these concepts and will encourage them to do research in the future.

7. When they were asked to express the main reasons that would motivate them to implement this activity in their classroom, the participants stated in general that:

- This activity is very simple and the materials are accessible.

We can think about other accessible and disposable materials that were presented in this workshop by the researchers.

- The experiments can be carried out quickly. Our student can repeat these activities in any place, such as home, because the materials are accessible, disposable, simple and it is so easy to design such apparatus.

- The students will be engaged and will feel part of the discovery process and they can easily design their own apparatus.

- The creativity of the students will definitively be simulated.

Analysis of teachers' statements that came from a paper survey to check their impressions about the activity has detected a range of professional descriptions reflecting changes in cognitive, pedagogical and emotional dimension, on the one hand, and various dilemmas, fears and doubts on the other.

The substantial improvement in the ability of teachers shows the high skill of teachers to process appropriate activities for students while going up a "step" in their professional development. The study findings indicate that, during the course, the teachers went through an evolutionary and professional change expressed in a transition from scientific evidence of their special field of knowledge, the type of experiments and materials they used and the conceptualization of all this, to the acquisition and implementation of work methods, other ways of dealing and thinking, in a different approach. The findings also indicate that there was progress in their will and ability to deal with the development and processing of materials originating in the spirit of this approach. Teachers indicated that they gained, as a result of the course, self-confidence and high skill of locating and processing other topics in chemistry that can be combined during experiments with materials available and not expensive.

The change that occurred in the perception of teachers as a result of the course can be attributed to two factors combined together. The first is raising teachers' awareness of the need and importance of processing such experiments; and the second, the way teachers were exposed as learners of events during the course in the context of Hoffman apparatus for electrolysis improved their skills and abilities to the possibility of future development of experiments and similar activities.

Some teachers are found in the midst of change process reflected in the fact that they are implementing teaching approaches and content in real and not easy manner, caught between the school reality that does not always allow making real change, and the desire to change. The real "test" of change in the attitude of teachers will be the implementation in the coming years. Awareness of the need for change and its nature already exists, based on the teachers' statements and the way they began to realize it, as reflected in the findings of this study.

After the significant developmental change expressed by many teachers following their planning, implementation and evaluation, it appears that, among teachers, a rise in the motivation to change was observed; in addition to recognizing the importance and profound understanding of the entire process. A possible outcome of teacher development at this stage will be the involvement of school teaching teams, where they function as agents of change to their colleagues. Continuation of the process of teacher development depends on the teacher himself, on the school support and the offered academic accompaniment.

\section{Conclusion}

The implementation of these activities with teachers from high school, and the analysis of the data collected from the participants corroborate the position of this paper. Although electrolysis can be a difficult subject to teach and perform experiments (given the common lack of resources available to teachers in high schools), teachers are motivated to experiment with and introduce these approaches in their classrooms and, with it, the content knowledge of the subject. The presented simple and familiar apparatus should make these experiments safely available at all levels in chemistry classes. Teachers that have conducted the aforementioned described experiments with plastic Hoffman apparatus have shown excitement and fun especially when observing visually occurring electrolysis. We believe that these workshops motivate the teachers to be more creative in designing new apparatuses in teaching and learning chemistry, and encouraging their students to be more active learning and creative in their classes.

The research described in this paper, has clear implications for action at school. This action depends on several factors, where teachers constitute the central link in the success. Expectations to make a real and comprehensive scientific change in the education system depend largely on the ability of professional development of teachers to lead real change in the classroom.

\section{REFERENCES}

Ben-Chaim, D., Joffe, N., \& Zoller, U. (1994). Empowerment of elementary school teachers to implement science curriculum reforms. School Science and Mathematics, 94, 356-366. doi:10.1111/j.1949-8594.1994.tb15694.x

Elliote, J. (1999). Introduction: Global and local dimentions of reforms in teacher education. Teaching and Teacher Education, 15, 133-141.

Hendricks, L. J., \& Williams, J. T. (1982). Demonstration of electrochemical cell properties by a simple, colorful, oxidation-reduction experiment (TD). Journal of Chemical Education, 59, 586. doi:10.1021/ed059p586

Hugerat, M. (2006). New prospects in teaching microscale electrolysis. In: M. Hugerat, P. Schwarz, \& M. Livneh (Eds.), Microscale chemistry experimentation for all ages (pp. 141-155). Nazareth: Al-Nahda Press.

Hugerat, M. (2008). New inexpensive apparatus for electrolysis. Chemical Education Journal, 11, 11-19.

http://chem.sci.utsunomiya-u.ac.jp/cejrnlE.html

Hugerat, M., Abu-Much, R., Basheer, A., \& Basheer, S. (2009). Using inexpensive to free materials to do electrolysis with all school ages. 
Chemical Education Journal, 13, 2.

http://chem.sci.utsunomiya-u.ac.jp/cejrnlE.html

Hugerat, M., \& Schwarz, P. (2008). Microscale electrolysis with disposable materials. Chemical Educator, 13, 7.

Scandholtz, J. H., \& Scribner, S. P. (2006). The paradox of administrative control in fostering teacher professional development. Teaching and Teacher Education, 22, 1104-1117. doi:10.1016/j.tate.2006.07.006

Shakhashiri, B. Z. (1992). Chemical demonstrations: A handbook for teachers of chemistry. The University of Wisconsin Press.

Singh, M., Szafran, Z., \& Pike, R. M. (1999). Microscale chemistry and green chemistry: Complementary pedagogies. Journal of Chemical Education, 76, 1684. doi:10.1021/ed076p1684

Thompson, J., \& Soyibo, K. (2002). Effects of lecture, teacher demonstration, discussions and practical work on 10th graders' attitudes to chemistry and understanding of electrolysis. Research in Science \& Technology Education, 20, 25-37. doi:10.1080/02635140220130902

Wallace, J., \& Louden, W. (1998). Curriculum change in science: Riding the waves of reforms. In: B. Fraster, \& K. Tobin (Eds.), International book of science education (pp. 471-485). London: Kluwer.

Wheeler, C. W., Gallagher, J., \& McDonough, M. (1995). Improving school community relations in Thailand: Social forestry, education and community participation. The Asian Educational Challenge. Albany, NY: SUNY Press.

Zhou, N., Habelitz-Tkotz, W., Giesler, D., El-Marsafy, M. K., Schwarz, P., Hugerat, M., \& Najdoski, M. (2005). Quantitative microscale chemistry experimentation. Journal of Science Education, 6, 84.

Zhou, R. E. (1996). How to offer the optimal demonstration of the electrolysis of water. Journal of Chemical Education, 73, 786. doi:10.1021/ed073p786

Zidani, S., Kortam, N., \& Hugerat, M. (2003). Teaching science through research. Journal of Science Education, 4, 35-38. 